\title{
DOENÇA CARDIOVASCULAR E PERIODONTITE: ANÁLISE DE SÉRIE DE CASOS AVALIANDO NÍVEIS DE PROTEÍNA C-REATIVA
}

\author{
CARDIOVASCULAR DISEASE AND PERIODONTITIS: CASE \\ SERIES ANALYSIS EVALUATING C-REATIVE PROTEIN LEVELS
}

Cinara Taís Silva de Noronha' ${ }^{1}$ Eduardo Sérgio Donato Duarte Filho ${ }^{2}$, Marianne de Vasconcelos Carvalho ${ }^{3}$, Pedro Tardelli Diniz Filgueira ${ }^{4}$

1. Graduada em Odontologia pela Universidade de Pernambuco - UPE. Pós-Graduanda em Saúde Pública - Faculdade Eficaz.

2. Doutor em Odontologia. Professor Adjunto de Odontologia da UPE e Professor de Odontologia do Centro Universitário Tabosa de Almeida ASCES-UNITA.

3. Doutora em Estomatopatologia. Professora Adjunta de Odontologia da Universidade de Pernambuco - UPE.

4. Doutorando em Odontologia pela UPE.

Palavras-chave:

Doenças Periodontais, Doenças

Cardiovasculares, Proteína C-Reativa.
Keywords:

Periodontal Disease, Cardiovascular Disease, C-Reactive Protein.

\section{RESUMO}

As periodontopatias podem ser dos principais fatores para o agravamento de doenças, como alterações cardiovasculares. Microrganismos e produtos bacterianos encontrados nessas condições provocam intensa produção de mediadores inflamatórios, incluindo a proteína C-reativa (PCR), marcador para cardiopatias. Avaliou-se a relação dos níveis plasmáticos de PCR em pacientes com doenças cardiovasculares (DCV) e periodontite. Uma série de quatro casos acompanhados/ concluídos na referida clínica (idade entre 24 e 61 anos, todos homens). Constatada a condição de periodontite, o periograma do sextante comprometido foi realizado, junto à requisição de exames para dosagem dos níveis plasmáticos de PCR, antes e após sessão de raspagem e alisamento radicular. Em 21 a 30 dias, um periograma reavaliativo foi realizado para análise comparativa das profundidades de sondagem e níveis de PCR antes e após a sessão de instrumentação. Houve redução de $13,7 \%$ (paciente " $\mathrm{A}$ ") e até $2 \mathrm{~mm}$ na perda de inserção (pacientes " $\mathrm{A}$ " $\mathrm{e}$ " $\mathrm{C}$ ") dos sítios avaliados; não houve nenhuma mudança significativa nas novas dosagens dos níveis de PCR. Conclui-se que não foi possível demonstrar uma correlação entre os níveis de PCR em pacientes que apresentam concomitantemente DCV e periodontite, nesta série de casos.

\section{INTRODUÇÃO}

A condição bucal dos indivíduos e sua influência em condições sistêmicas vem sendo amplamente discutida na comunidade científica, estudos sugerem que as infecções orais, principalmente as doenças periodontais, surgem como um dos principais fatores para o agravamento e aparecimento de doenças devido ao seu caráter infeccioso e inflamatório persistente, sendo as doenças cardiovasculares as mais comumentes associadas a pacientes com periodontite ${ }^{1,2,3}$.

As doenças periodontais consistem em processos inflamatórios, de origem bacteriana e infecciosa que podem acometer o periodonto de proteção e/ou periodonto de inserção, podem estar associadas a fatores sistêmicos e/ou locais, caracterizadas por inflamação gengival e perda óssea ${ }^{4,5}$. 
O aumento desse número de bactérias na cavidade oral provoca uma resposta inflamatória e uma intensa produção de mediadores inflamatórios como as interleucinas (IL) e fator de necrose tumoral (TNF), assim como a proteína C-reativa (PCR). Produzida no fígado, a PCR é encontrada principalmente na fase aguda de determinadas doenças e pode ser considerada um novo marcador para as doenças cardiovasculares ${ }^{4}$, ainda que inespecífico. As doenças cardiovasculares (DCV) constituem uma das principais causas de mortalidade no mundo ${ }^{6,7}$, suas principais manifestações clínicas ocorrem sob a forma de infarto agudo do miocárdio e acidentes vasculares cerebrais, com maior prevalência em indivíduos entre os 50 e 70 anos $^{8}$.

A aterosclerose, considerada uma das causas primárias das doenças cardiovasculares, possui aspectos inflamatórios em seu processo e marcadores pró-inflamatórios são produzidos, destacando-se a Interleucina 6 (IL-6), o TNF e a PCR que poderiam atuar, mesmo que de modo inespecífico, como indicadores de risco para as doenças cardiovasculares ${ }^{8}$. A inflamação desempenha um papel de significância em todos os estágios de desenvolvimento da lesão aterosclerótica e a natureza infecciosa e/ou inflamatória das doenças periodontais parecem ratificar a hipótese de envolvimento destas doenças com a formação da placa ateromatosa ${ }^{9}$.

Evidências literárias associam a doença periodontal às doenças coronárias através da estimulação da via de coagulação, induzida pela PCR, intimamente relacionada a disfunção endotelial, provocando os monócitos e macrófagos a produzir fator tecidual, levando a um aumento da coagulação sanguínea, além de estimular a cascata do sistema complemento, exacerbando ainda mais o processo inflamatório ${ }^{9,10}$. A PCR vem sendo utilizada rotineiramente para avaliação de pacientes que possuem alguma desordem inflamatória, em condições normais seus níveis são em média entre 0,25 e 0,5mg/dl, podendo ser aumentado de 100 até 1000 vezes durante processos inflamatórios ${ }^{11}$.

Embora a periodontite crônica seja considerada uma doença inflamatória de baixo grau, uma exacerbação dessa condição pode aumentar os níveis sanguíneos de IL- 6 e PCR, que podem precipitar infarto do miocárdio e acidentes vasculares cerebrais ${ }^{3,9}$. Em vista do exposto, objetivou-se avaliar a relação dos níveis plasmáticos de PCR em uma série de casos de doenças cardiovasculares (DCV) e periodontite na clínica odontológica.

\section{MATERIAL E MÉTODOS}

Estudo exploratório, quanti-qualitativo, analítico e observacional, com característica clínico-epidemiológica, com apreciação e aprovação pelo Comitê de Pesquisa (CEP/UPE sob o Parecer $n^{\circ}$ 2.108.205). A amostra foi realizada por conveniência, com pacientes que procuraram a clínica odontológica da Universidade de Pernambuco/Campus Arcoverde (COUPECA), que apresentavam concomitantemente doenças cardiovasculares e periodontite. A coleta de dados foi dividida em três (3) fases. Inicialmente, os pacientes selecionados foram submetidos à realização do Registro Periodontal Simplificado com instrumentais e materiais devidamente esterilizados em autoclave e utilização de sonda periodontal (OMS). Tal exame forneceu subsídios para estimar a presença de bolsas periodontais/periodontite nestes pacientes (todos não fumantes), através do código 3 e $4^{12}$ (Figura 1).

\begin{tabular}{|c|c|c|}
\hline $\begin{array}{c}\text { CÓDIGO } \\
0\end{array}$ & $\begin{array}{l}\text { Faixa colorida totalmente visivel, sem } \\
\text { sangramento a sondagem, ausência de cálculo } \\
\text { e excessos de margens restauradoras. }\end{array}$ & Manter o paciente sob medidas preventivas \\
\hline $\begin{array}{c}\text { CÓDIGO } \\
1\end{array}$ & $\begin{array}{l}\text { Faixa colorida totalmente visivel, com } \\
\text { sangramento a sondagem, ausência de cálculo } \\
\text { e excessos de margens restauradoras. }\end{array}$ & $\begin{array}{l}\text { Eliminação de placa pelo profissional e instrução } \\
\text { de higiene oral }\end{array}$ \\
\hline $\begin{array}{c}\text { CÓDIGO } \\
2\end{array}$ & $\begin{array}{l}\text { Faixa colorida totalmente visível, com } \\
\text { sangramento a sondagem, presença de cálculo } \\
\text { supra e/ou subgengival e/ou excessos de } \\
\text { margens restauradoras. }\end{array}$ & $\begin{array}{l}\text { Raspagem e polimento, remoção dos excessos } \\
\text { de restaurações e instruçăo de higiene oral }\end{array}$ \\
\hline $\begin{array}{c}\text { CÓDIGO } \\
3\end{array}$ & $\begin{array}{l}\text { Faixa colorida parcialmente visivel, presença de } \\
\text { bolsa de } 3,5 \text { a } 5,5 \mathrm{~mm} \text {. }\end{array}$ & $\begin{array}{l}\text { Necessidade de exame periodontal } \\
\text { complementar no sextante com periograma, } \\
\text { radiografias. Indica necessidade de tratamento } \\
\text { periodontal especializado no sextante }\end{array}$ \\
\hline $\begin{array}{c}\text { CÓDIGO } \\
4\end{array}$ & $\begin{array}{l}\text { Faixa colorida não visivel, presença de bolsa } \\
\text { periodontal acima de } 5,5 \mathrm{~mm} \text {. }\end{array}$ & $\begin{array}{l}\text { Necessidade de exame periodontal } \\
\text { complementar no sextante com periograma, } \\
\text { radiografias. Indica necessidade de tratamento } \\
\text { periodontal especializado e complexo no sextante }\end{array}$ \\
\hline CÓDIGO* & $\begin{array}{l}\text { A inserção deste código significa a presença de } \\
\text { outros problemas como envolvimento de furcas, } \\
\text { mobilidade, perda de gengiva inserida e recessão } \\
\text { gengival acima de } 3.5 \mathrm{~mm} \text {. }\end{array}$ & \\
\hline
\end{tabular}

Figura 1 - Códigos do Registro Periodontal Simplificado-RPS (Santos Junior et al. ${ }^{24}$ ) 
Constatada a condição da doença periodontal de cada paciente, foi solicitada uma avaliação cardiológica com determinação de ASA (American Society of Anesthesiologists) com fins de determinar a inclusão ou não dos pacientes examinados, sabendo-se que os pacientes deveriam apresentar ASA II ou III. Os pacientes selecionados foram submetidos à realização de um exame periodontal detalhado (periograma) objetivando classificar as periodontites dos pacientes quanto à severidade e extensão, contudo, principalmente, registrar (em milímetros) a profundidade das bolsas periodontais a serem tratadas.

Concluído o periograma, foi requisitado aos pacientes exame hematológico para dosagem dos níveis de PCR.

A segunda fase correspondeu à uma sessão de raspagem e alisamento radicular nos sítios acometidos, na COUPECA, através de instrumentação radicular manual (curetas) e ultrassônica. Finalizada a intervenção, os pacientes receberam instruções de higiene oral individualizadas, buscando potencializar o sucesso da terapia periodontal empregada. Os pacientes foram orientados a retornar à COUPECA em cerca de 30 dias, trazendo consigo uma nova dosagem dos níveis de PCR, havendo instrução para que os pacientes somente fossem submetidos à coleta sanguínea 21 dias após a instrumentação radicular.

Na última fase, os pacientes foram submetidos a um periograma reavaliativo. Os novos níveis plasmáticos de PCR foram registrados. Os parâmetros periodontais iniciais e finais, bem como os níveis de PCR foram compilados e comparados. Para registro do periograma inicial e reavaliativo, foi utilizada a ficha clínica periodontal do Curso de Odontologia da UPE/Campus Arcoverde.

Analisaram-se os dados obtidos através dos exames laboratoriais e periogramas utilizando-se o programa Microsoft Excel versão 2013 e os resultados foram apresentados na forma de tabelas e gráficos, com valores absolutos e relativos.

\section{ANÁLISE DA SÉRIE DE CASOS}

Foram avaliados 7 pacientes, contudo, apenas 4 completaram as fases propostas pela metodologia. A idade dos voluntários concluinte da pesquisa variou de 24 a 61 anos, sendo a média 47 anos, todos do sexo masculino e moradores do município de Arcoverde.

Referente às condições cardiovasculares dos pacientes concluídos, $75 \% \quad(n=3)$ possuíam hipertensão arterial e $25 \%(n=1)$ arritmia cardíaca; todos os pacientes $(n=4)$ apresentavam ASA II, segundo avaliação cardiológica. De acordo com o Registro Periodontal Simplificado (RPS), de todos os sextantes avaliados $(n=21)$, considerando que um dos voluntários era edêntulo total superior, $66,6 \%(n=14)$ apresentavam periodontite, destes, em $71,4 \%(n=10)$ foram registrados código 3 (referente a profundidades de sondagem entre $3,5 \mathrm{~mm}$ e $5,5 \mathrm{~mm}$ ) e em $28,6 \%(\mathrm{n}=4)$ código 4 (referente a bolsas periodontais acima de $5,5 \mathrm{~mm}$ ), sendo o sextante VI o mais acometido por doença periodontal tanto no código 3 quanto no código $4,40 \%(n=10)$ e $50 \%(n=2)$ respectivamente.

Os $42,9 \%(n=3)$ pacientes que realizaram apenas metade das fases propostas, eram duas do sexo feminino e um do sexo masculino apresentando hipertensão arterial sistêmica. Dos sextantes avaliados ( $n=18)$, em $66,6 \%(n=12)$ foi constatada doença periodontal, $58,3 \%(n=7)$ referentes ao código 3 e $41,7 \%(n=5)$ ao código 4; a dosagem inicial dos exames de PCR variou de $0,1 \mathrm{mg} / \mathrm{l}$ a $<6 \mathrm{mg} / \mathrm{dl}$. No periograma inicial foi diagnosticado periodontite moderada em um dos pacientes e periodontite severa nos demais $(n=2)$.

Após a realização do periograma, previamente ao tratamento de raspagem e alisamento coronorradicular, em 312 sítios sondados, correspondentes aos sextantes acometidos por periodontite dos pacientes concluídos $(n=4)$, as profundidades de sondagens mais expressivas variaram de $4 \mathrm{~mm}$ a $6 \mathrm{~mm}$, havendo retração gengival de até $5 \mathrm{~mm}$ em $8 \%(n=25)$ dos sítios avaliados e foi constatado perda de inserção em 25,3\% $(n=79)$ dos sítios. Quanto à severidade da periodontite, foi encontrado periodontite leve em $50 \%(n=2)$ dos pacientes, periodontite moderada em $25 \%(n=1)$ e periodontite severa em $25 \%(n=1)$.

Quanto à extensão da periodontite, em 75\% dos pacientes $(n=3)$ foi constatado periodontite localizada, com números variando entre $8,3 \%$ e $27,5 \%$ de sítios acometidos, em $25 \% \quad(n=1)$ paciente foi encontrado periodontite generalizada, acometendo $50 \%$ dos sítios avaliados (Tabela 1).

Tabela 1 - Frequência absoluta e relativa da extensão da periodontite dos voluntários concluídos na pesquisa antes e após terapia periodontal.

\begin{tabular}{ccc}
\hline Voluntário & $\begin{array}{c}\text { Antes da terapia } \\
\text { periodontal }\end{array}$ & $\begin{array}{c}\text { Após a terapia } \\
\text { periodontal }\end{array}$ \\
\hline A & $27,5 \%-38$ sítios & $13,7 \%-19$ sítios \\
B & $8,3 \%-5$ sítios & $6,6 \%-4$ sítios \\
C & $50 \%-18$ sítios & $5,5 \%-2$ sítios \\
D & $23 \%-18$ sítios & $7,6 \%-6$ sítios \\
\hline
\end{tabular}

Após uma sessão de instrumentação periodontal, o novo periograma foi realizado nos pacientes concluídos $(n=4)$, encontrando uma redução de $13,7 \%(n=42)$ e até $2 \mathrm{~mm}$ na perda de inserção dos sítios avaliados. Não houve nenhuma mudança significativa nas novas dosagens dos níveis de PCR. Detalhadamente os dados comparativos podem ser observados na Tabela 2.

Em relação às dosagens dos níveis de $\mathrm{PCR}$ previamente à terapia periodontal, $50 \%(\mathrm{n}=2)$ apresentaram $<6 \mathrm{mg} / \mathrm{l}$, enquanto $25 \%$ ( $n=1)$ o nível foi de $0,3 \mathrm{mg} / \mathrm{l}$ e $25 \%(n=1)$ de $0,5 \mathrm{mg} / \mathrm{l}$. O comparativo entre profundidades de sondagem e níveis de PCR estão expressos na Figura 2 
Doença cardiovascular/periodontite: PCR

Noronha CTS, et al.

Tabela 2 - Severidade da periodontite dos voluntários avaliados na pesquisa antes e após terapia periodontal

\begin{tabular}{|c|c|c|c|c|c|c|}
\hline \multirow[b]{2}{*}{ Voluntário } & \multicolumn{3}{|c|}{ Antes da terapia periodontal } & \multicolumn{3}{|c|}{ Após a terapia periodontal } \\
\hline & $\begin{array}{l}\text { Condição } \\
\text { Geral }\end{array}$ & $\begin{array}{l}\text { Condição por } \\
\text { Sextante }\end{array}$ & $\begin{array}{l}>P S^{*} \\
(\mathrm{~mm})\end{array}$ & $\begin{array}{l}\text { Condição } \\
\text { Geral }\end{array}$ & $\begin{array}{l}\text { Condição por } \\
\text { Sextante }\end{array}$ & $\begin{array}{l}>\mathrm{PS}^{*} \\
(\mathrm{~mm})\end{array}$ \\
\hline \multirow[t]{6}{*}{$A$} & Severa & I - Leve & 5 & Severa & I- Leve & 4 \\
\hline & & II - Leve & 4 & & II - Leve & 4 \\
\hline & & III - Severa & 6 & & III - Severa & 4 \\
\hline & & IV - Severa & 6 & & IV - Moderada & 4 \\
\hline & & V - Severa & 5 & & V-Severa & 3 \\
\hline & & VI - Severa & 6 & & VI - Leve & 4 \\
\hline \multirow[t]{6}{*}{ B } & Moderada & I- Moderada & 6 & Moderada & I - Leve & 5 \\
\hline & & II - Não acometido & $\mathrm{N}^{* *}$ & & II - Não acometido & $\mathrm{N}^{* *}$ \\
\hline & & III - Não acometido & $N^{* *}$ & & III - Não acometido & $N^{* *}$ \\
\hline & & IV - Não acometido & $\mathrm{N}^{* *}$ & & IV - Não acometido & $\mathrm{N}^{* *}$ \\
\hline & & V - Não acometido & $\mathrm{N}^{* *}$ & & V - Não acometido & $\mathrm{N}^{* *}$ \\
\hline & & VI - Moderada & 5 & & VI - Leve & 4 \\
\hline \multirow[t]{6}{*}{ C } & Leve & I- Ausente & $N^{* *}$ & Leve & I-Ausente & $\mathrm{N}^{* *}$ \\
\hline & & II - Ausente & $\mathrm{N}^{* *}$ & & II - Ausente & $\mathrm{N}^{* *}$ \\
\hline & & III - Ausente & $N^{* *}$ & & III - Ausente & $N^{* *}$ \\
\hline & & IV - Leve & 5 & & IV - Leve & 3 \\
\hline & & V-Leve & 4 & & V - Saudável & 3 \\
\hline & & VI - Leve & 4 & & VI - Saudável & 2 \\
\hline \multirow[t]{6}{*}{$D$} & Leve & I - Leve & 5 & Leve & I - Leve & 5 \\
\hline & & II - Não acometido & $\mathrm{N}^{* *}$ & & II - Não acometido & $\mathrm{N}^{* *}$ \\
\hline & & III - Leve & 4 & & III - Leve & 3 \\
\hline & & IV - Leve & 4 & & IV - Saudável & 3 \\
\hline & & V - Não acometido & $\mathrm{N}^{* *}$ & & V - Não acometido & $\mathrm{N}^{* *}$ \\
\hline & & VI - Leve & 4 & & VI - Leve & 4 \\
\hline
\end{tabular}

* PS = Maior profundidade de sondagem

** $\mathrm{N}=$ Normal

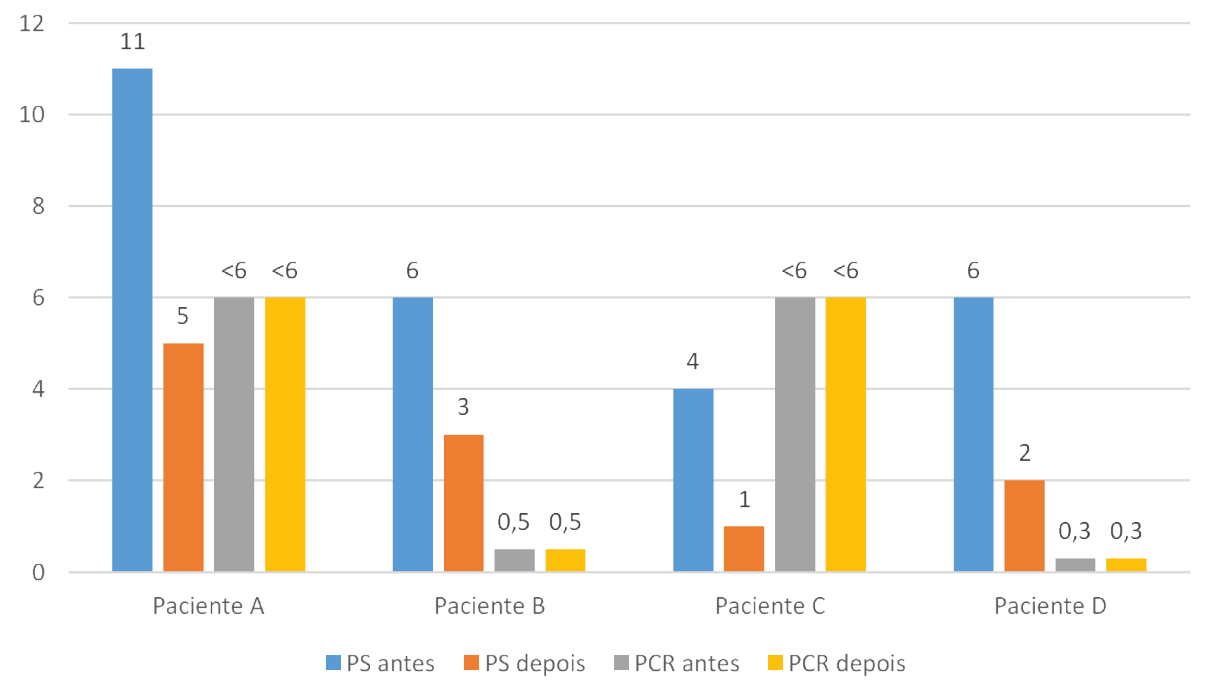

Figura 2 - Análise comparativa dos níveis de Profundidade de Sondagem (PS) e níveis de PCR antes e após instrumentação periodontal 


\section{DISCUSSÃO}

Após a análise dos resultados, apesar do número reduzido da amostra, pode-se observar uma prevalência de periodontite em indivíduos de em média 47 anos, faixa etária que está, segundo o Levantamento Epidemiológico SB Brasil ${ }^{13}$, entre as quais as doenças periodontais são mais prevalentes, acometendo cerca de $18,2 \%$ dos adultos entre 35 e 44 anos e $3,8 \%$ nos idosos entre 65 e 74 anos.

Quanto aos sextantes avaliados na pesquisa $(n=39)$, incluindo pacientes concluídos e pacientes que concluíram apenas metade da metodologia proposta, 66,6\% ( $n=26)$ apresentavam perda de inserção periodontal. Com uma amostra bastante expressiva, 335 idosos, um estudo foi realizado avaliando a condição bucal dos indivíduos e obteve dado semelhante ${ }^{14}$. A condição periodontal foi avaliada com sonda Carolina do Norte e os dentes índices $(17,16$, $11,26,27,46,31,36$ e 37) preconizados pela OMS ${ }^{15}$ foram os elementos considerados, constatando-se a presença de doença periodontal em $64,5 \%$ dos sextantes analisados. Ainda em comparação com o estudo supracitado, que encontrou bolsas periodontais de 4 a $5 \mathrm{~mm}$ em $64,5 \%$ dos sítios avaliados, $71,4 \%$ das bolsas periodontais encontradas nos indivíduos do presente trabalho eram de 3,5 a 5,5 $\mathrm{mm}$.

Assim como nas periodontopatias, indivíduos acima de 40 anos são os mais acometidos por doenças cardiovasculares ${ }^{8,16}$. Acredita-se que essa relação seja decorrente do aumento dos níveis de marcadores próinflamatórios provocados pela doença periodontal, incluindo a PCR, que constituem indicadores de risco para as doenças cardiovasculares ${ }^{1,8,17}$. De acordo com a literatura, as doenças cardiovasculares são responsáveis por cerca de $30 \%$ das mortes em indivíduos acima de 30 anos, acometendo principalmente indivíduos do sexo masculino ${ }^{18}$, gênero este que compõe $71 \%(n=5)$ dos indivíduos avaliados na presente pesquisa.

Referente às condições cardiovasculares encontradas, $85,7 \% \quad(n=6)$ dos pacientes avaliados apresentavam hipertensão arterial e 14,3\% $(n=1)$ arritmia cardíaca; a literatura considera a hipertensão arterial um dos principais fatores de risco para doenças referentes ao coração e aos vasos sanguíneos ${ }^{16,19,20}$. Devido a sua alta prevalência, principalmente em idosos, a hipertensão arterial possui alta relevância na morbidade e mortalidade dos indivíduos ${ }^{16}$.

Diversos estudos $2,3,17,21,22$ demonstraram uma estreita relação entre periodontopatias e doenças cardiovasculares. Pesquisadores analisaram alguns estudos realizados entre os anos de 1963 a 2002 sobre associação entre doenças cardiovasculares e doenças periodontais e a maioria dos estudos demonstrou alguma influência da condição bucal nos níveis aumentados de PCR em pacientes cardiopatas, indicando uma relação positiva entre doença periodontal e doença cardiovascular ${ }^{17}$

Accarini e Godoy $^{21}$ relacionando a doença periodontal com as doenças cardiovasculares, avaliaram 325 pacientes internados na UTI com síndromes coronarianas agudas; destes, 28\% apresentavam discreta ou nenhuma obstrução, o restante apresentava obstrução importante.
Foi avaliada profundidade clínica de sondagem, nível de inserção clínica, índices de biofilme e gengival. Ao final dos exames, percebeu-se 2,5 mais vezes possibilidade de presença de doença periodontal nos pacientes com síndrome coronariana aguda e coronariopatia obstrutiva significante.

Houve uma redução, após uma sessão de terapia periodontal, de até $13,7 \% \quad(n=42)$ na perda de inserção dos sítios avaliados, ratificando a eficiência da raspagem e alisamento coronorradicular no tratamento da doença periodontal. Resultado semelhante foi visto em um estudo realizado por Andrade ${ }^{23}$ no qual foram avaliados 48 indivíduos diagnosticados com periodontite crônica e analisados critérios como nível de inserção clínica e profundidade de sondagem antes e após a terapia periodontal básica. Foi encontrado melhora significativa em todos os parâmetros clínicos avaliados após o tratamento periodontal.

Em relação aos níveis de PCR, dos indivíduos inclusos na pesquisa, um dos pacientes não concluídos apresentou níveis de PCR considerado fora dos padrões da normalidade, 0,01 mg/l, enquanto nos pacientes concluídos em um deles foi encontrado o valor de $0,5 \mathrm{mg} / \mathrm{l}$, considerado valor limite nos padrões de normalidade. Segundo Bezerra et al. ${ }^{11}$ em condições normais os níveis de PCR variam entre 0,25 e $0,5 \mathrm{mg} / \mathrm{l}$.

Correia e colaboradores ${ }^{22}$ buscando identificar fatores preditores para aumento dos níveis de PCR, realizaram um estudo com 88 indivíduos de baixo nível socioeconômico em comparação com 32 indivíduos de classe econômica alta, para avaliar os níveis de PCR. Concluíram que adiposidade, fumo e infecções crônicas são fatores contribuintes para níveis aumentados de PCR em indivíduos de baixo nível sócioeconômico, tendo destaque principalmente para as infecções crônicas. Sabendo-se que a doença periodontal trata-se de uma condição infecciosa de cronicidade, o estudo pode elucidar a associação das periodontopatias com as doenças cardiovasculares.

Provavelmente, devido ao número limitado da amostra, esses resultados não estão em consonância com o estudo proposto por Arregocés e colaboradores ${ }^{2}$ por exemplo, os quais realizaram um estudo com 401 indivíduos com idade entre 30 e 75 anos, incluindo caso e controle, para verificar a relação entre diabetes mellitus, doença periodontal e pacientes com e sem infarto do miocárdio e, verificaram que os níveis de $P C R$ são aumentados em pacientes que possuem periodontopatias, diabetes mellitus e doenças coronárias. Anitha e colaboradores ${ }^{3}$ ressaltaram em seu trabalho a predisponência de pacientes com periodontite a desenvolver doenças cardíacas. O estudo avaliou os níveis de PCR em 100 pacientes com doença periodontal e sem alterações coronárias. Nos pacientes portadores de periodontite crônica, puderam perceber um aumento nos níveis de PCR, tratando-se de um efetivo marcador de risco para as doenças coronárias.

O risco cardiovascular originado por infecções crônicas, como a doença periodontal, pode ser explicado pela entrada de patógenos na corrente sanguínea. Alguns patógenos periodontais, em especial, podem atuar no processo de aterosclerose tanto na resposta imunológica, 
induzindo a produção exacerbada de mediadores inflamatórios, incluindo a PCR, quanto na extensão e estabilidade da placa aterosclerótica ${ }^{23}$.

Pacientes com níveis elevados de proteína C-reativa estão sob o risco de desenvolver alterações coronarianas; coincidentemente os níveis de PCR são aumentados principalmente em indivíduos com infecções crônicas, com destaque para doença periodontal moderada e severa, em casos de infecções orais, afirmando a relação entre PCR e doença periodontal e destacando a importância dos cuidados com a saúde bucal para manutenção de um órgão sistemicamente saudável ${ }^{11}$. Telles e Wang ${ }^{9}$ acreditam que o mecanismo que associa as doenças periodontais com as doenças coronárias, seja feito através da estimulação da via de coagulação, induzida pela PCR, intimamente relacionada a disfunção endotelial, provocando os monócitos e macrófagos a produzir fator tecidual, levando a um aumento da coagulação sanguínea, além de estimular a cascata do sistema complemento, exacerbando ainda mais o processo inflamatório.

\section{CONSIDERAÇÕES FINAIS}

Apesar da literatura demonstrar uma possível correlação entre os níveis de proteína C-reativa em pacientes que apresentam concomitantemente alterações cardiovasculares e periodontite, no presente trabalho essa correlação não foi visualizada, fato que pode estar fortemente relacionado ao número reduzido da amostra.

\section{REFERÊNCIAS}

1. Almeida RF, Pinho MM, Lima C, Faria I, Santos P, Bordalo C. Associação entre doença periodontal e patologias sistêmicas. Rev Port Clin Geral. 2006;22(3):379-90.

2. Arregoces FE, Uriza CL, Porras JV, Camargo MBF, Morales AR. Relation between ultra-sensitive C-reactive protein, diabetes and periodontal disease in patients with and without myocardial infarction. Arq Bras Endocrinologia Metab. 2014;58(4):362-68.

3. Anitha V, Nair S, Shivakumar V, Shanmugam M, Priya BM, Rajesh P. Estimation of high sensitivity C-reactive protein in patients with periodontal disease and without coronary artery disease. Indian Journal of Dental Research. 2015;26(5):500-503.

4. Souza E, Lopes JCA, Gaspar Junior AA, Silva K, Silva AS, Silva $E$, et al. A doença periodontal como fator de risco para as doenças cardiovasculares. International Journal of Denstistry. 2006;1(2).

5. Araújo MG, Sukekava F. Epidemiologia da doença periodontal na América Latina. Rev Periodontia. 2007;17(2):7-13.

6. Mansur AP, Favarato D. Mortalidade por doenças cardiovasculares no Brasil e na região metropolitana de São Paulo: atualização 2011. Arq Bras Cardio. 2012;99(2):755-61.
7. Ribeiro AG, Cotta RMM, Ribeiro SMR. A promoção da saúde e a prevenção integrada dos fatores de risco para doenças cardiovascularess. Ciência e Saúde Coletiva. 2012;17(1):7-17.

8. Ramos AM, Pellanda LC, Gus I, Portal VL. Marcadores inflamatórios da doença cardiovascular em idosos. Arq Bras Cardiol. 2009;92(3):233-240.

9. Telles R, Wang CY. Mechanisms involved in the association between periodontal diseases and cardiovascular disease. Oral Dis. 2011;17(5):450-461.

10. Freitas COL, Gomes Filho IS, Naves RC, Nogueira Filho GR, Cruz SS, Santos CAST, et al. Influence of periodontal therapy on C-reactive protein level: a systematic review and metaanalysis. Journal Appl Oral Sci. 2012;20(1):1-8.

11. Bezerra CFR, Amaral BA, Camelo FP, Aquino ARL, Seabra EG, Carreiro AFPO. O papel da proteína C-reativa na relação entre as doenças periodontais e cardiovasculares. Rev Periodontia. 2008;18(1):7-13.

12. Santos Júnior GC, BarnabéW, Rubo JH, Greghi SLA. Avaliação Periodontal Simplificada (PSR) em pacientes indicados para tratamento protético. Periodontal Screening and Recording (PSR) evaluation of patients indicated for prosthetic treatments. Rev Fac Odontol Bauru. 2002;10(2):113-7.

13. Brasil, Secretaria de Atenção à Saúde, Secretaria de Vigilância em Saúde. SB Brasil 2010: Pesquisa Nacional de Saúde Bucal: resultados principais. Brasília: Ministério da Saúde. 2012;116.

14. Ferreira RC, Magalhães CS, Rocha ES, Schwambach CW, Moreira AN. Saúde Bucal de idosos residentes em instituições de longa permanência de Belo Horizonte, Minas Gerais, Brasil. Cad Saúde Pública. 2009;25(11):2375-2385.

15. World Health Organization. Oral health surveys: basic methods. 4 ed. Geneva: World Health Organization.1997.

16. Liberman A. Aspectos epidemiológicos e o impacto clínico da hipertensão no individuo idoso. Rev Bras Hipertens. 2007;14(1):17-20.

17. Silva FR, Goiris FAJ, Pilatti GL, Santos FA. Relação entre doença periodontal e proteína C-reativa em pacientes com doença cardiovascular - revisão de literatura. Ci Biol Saúde. 2007;13(3/4):53-58.

18. Brasil, Ministério da Saúde. Doenças cardiovasculares causam quase $30 \%$ das mortes no país. Disponível em <http://www.brasil.gov.br/editoria/saude/2011/09/ doencas-cardiovasculares-causam-quase-30-das-mortesno-pais> 2017. Acesso em 23 de junho de 2018.

19. Cesarino CB, Cipullo JP, Martin JFV, Ciorlia LA, Godoy MRP, Cordeiro JA, et al. Prevalência e fatores sociodemográficos em hipertensos de São José do Rio Preto - SP. Arq Bras Cardiol. 2008;91(1):31-35.

20. Passos VMA, Assis TD, Barreto SM. Hipertensão arterial no Brasil: estimativa de prevalência a partir de estudos de base populacional. Epidemiologia e Serviços de Saúde. 2006;15(1):35-45.

21. Accarini R, Godoy MF. Doença periodontal como potencial fator de risco para síndromes coronarianas agudas. Arq Bras Cardiol. 2006;87(5):592-596. 
Doença cardiovascular/periodontite: PCR

Noronha CTS, et al.

22. Correia LCL, Penalva R, Correia $\mathrm{H}$, Ladeia AM, Menezes $\mathrm{M}$, Suzart I, et al. Determinantes do valor da proteína C-reativa em indivíduos de nível sócio-econômico muito baixo. Arq Bras Cardiol. 2010;94(2):216-23.

23. Andrade NK, Brandão RLCM, Barros AW. Avaliação da eficácia das terapias periodontais básicas realizadas pelos graduandos de Odontologia no Centro Universitário CESMAC, Maceió, Brasil. Rev ACBO 2018;8(1): 65-72.

24. Santos Júnior GC, BarnabéW, Rubo JH, Greghi SLA. Avaliação Periodontal Simplificada (PSR) em pacientes indicados para tratamento protético. Periodontal Screening and Recording (PSR) evaluation of patients indicated for prosthetic treatments. Rev Fac Odontol Bauru. 2002;10(2):113-7. 